\title{
Larval omnivory in Amara aenea (Coleoptera: Carabidae)
}

\author{
KAREL HŮRKA and VOJTĚCH JAROŠÍK
}

Department of Zoology, Charles University, Viničná 7, CZ-128 44 Praha 2, Czech Republic; e-mail: hurka@natur.cuni.cz

Key words. Carabids, Amara aenea, larval diet, life histories, seed predation

\begin{abstract}
The duration of development, survivorship and adult size were compared for the larvae of Amara aenea reared in the first generation on pure diets of seeds (Stellaria media, Capsella bursa-pastoris, Tussilago farfara, Plantago major, Urtica dioica, or Potentilla argentela), or a pure diet of yellow mealworms (Tenebrio molitor larvae), and on a mixed diet of seeds and mealworm larvae (T. molitor, S. media and C. bursa-pastoris). To ascertain any long-term effects of pure diets, the beetles were reared on the same pure diet for several generations, or on different pure diets in different generations. The hypothesis that the larvae are primary omnivorous was tested. The evidence that the larvae of $A$. aenea are primary omnivorous was obtained by revealing that the larvae reared on the mixed diet of insects and seeds survived better, and developed faster in larger adults than those reared on the pure diets of seeds or insects. When the beetles were reared on the same pure diet for several generations, survivorship, and in most cases also the duration of development, did not change. However, when the beetles were reared on a different pure diet each generation, survivorship significantly decreased in successive generations.
\end{abstract}

\section{INTRODUCTION}

The adults of the genus Amara Bonelli (Coleoptera: Carabidae) are generally considered granivorous, since many have been observed feeding on flower heads or plant-seeds (Kleine, 1912, 1914; Burmeister, 1939; Lindroth, 1945; Burakowski, 1967; Forsythe, 1982; Hůrka, 1996; Luka et al., 1998). Although dissections (Hengeveld, 1980) and rearing experiments (Bílý, 1971; 1972; 1975; Hůrka \& Ducháč, 1980a, b; Hůrka, 1998) revealed that the adults also eat animal food, the abundance of adults of several species is significantly higher in weedy than weedless fields (Jarošík \& Hůrka 1986; Kokta, 1988; de Snoo et al., 1995; Honěk \& Jarošík, 2000; Honěk et al., 2003) and the fecundity of females of $A$. similata (Gyllenhal) is highest when reared on a diet of a mixture of weed-seeds (Bracht Jørgensen \& Toft, 1997). Therefore, seeds are the preferred food of adults of several Amara species and a potential food of their larvae.

For a long time the larvae of the genus Amara were regarded as insectivorous (e.g. Burakowski, 1967; Luff, 1993), only occasionally eating plant roots (Burmeister, 1939). Consequently, Amara larvae were usually fed an insect diet in the laboratory (Bílý, 1971, 1972, 1975; Hůrka \& Ducháč, 1980a, b; Desender et al., 1986; Desender, 1988, Hůrka, 1998; Hůrka \& Jarošík, 2001). The granivory of Amara larvae was first suggested by Thompson (1979) and Hưrka (1998) who successfully reared some species on a diet of oat flakes. The first convincing evidence that Amara larvae are granivorous was obtained by Bracht Jørgensen \& Toft (1997) that recorded that the lowest mortality of larvae of $A$. similata occurred when they fed on seeds of Capsella bursa-pastoris. Morphological features (e.g. broad larval mandibles) also suggest a seed-feeding adaptation (Zetto Brandmayr et al., 1998).
Recently, an investigation of nine closely related Amara species suggested that their larvae can be divided into granivorous, omnivorous and insectivorous forms (Saska \& Jarošík, 2001). In this study, larvae of Amara aenea (De Geer), one of the most common and important species, were reared on a range of diets. This species overwinters in the adult form and then develops as larvae in the spring and early summer (Hůrka, 1996). The hypothesis that the larvae are primary omnivorous (Saska \& Jarošík, 2001) was tested. The duration of development, survivorship and adult size was compared for larvae reared in the first generation on either pure diets of seeds, or on a mixed diet of seeds and insect larvae. To ascertain any long-term effects of pure diets, the beetles were reared on the same pure diet for several generations, and on a different pure diet in different generations.

\section{MATERIAL AND METHODS}

Laboratory experiments were performed in four seasons (1998-2001). Adults were collected in the field at several localities in the vicinity of Prague $\left(50^{\circ} \mathrm{N}, 14^{\circ} \mathrm{E}\right)$. The beetles were individually picked from the ground or collected using unbaited pitfall traps at the onset of the breeding period in spring. Beetles were transported in plastic bottles $(100-250 \mathrm{ml}$, filled with damp substrate and closed with a lid that allowed air circulation), and then placed into rearing vials.

The rearing of larvae followed Hůrka (1996). Breeding pairs were placed in glass vials (diameter $12 \mathrm{~cm}$, height $7 \mathrm{~cm}$ ) containing a 3-4 cm deep layer of a sieved garden soil and covered by gauze. A flat stone placed on the top of the substrate served as a natural shelter. Food was supplied ad libitum and placed in the centre of the vials, and changed twice a week to avoid the development of mould or the propagation of mites. Mouldy food or substrate was removed immediately. Humidity was kept high by moistening the substrate. Both adults and pre-imaginal stages were kept at $21 \pm 1^{\circ} \mathrm{C}$, under natural photoperiod $\left(50^{\circ} \mathrm{N}\right)$.

The breeding pairs were initially examined twice a week or, following the discovery of the first egg or larva, daily. The eggs 
were laid and the larvae sheltered in the substrate. Each day, larvae were removed from the substrate with a pair of forceps after spreading substrate on a photographic tray. Both eggs and larvae were transferred individually into petri dishes (diameter 6 $\mathrm{cm}$, height $1.5 \mathrm{~cm}$ ), containing a $0.5 \mathrm{~cm}$ layer of a garden soil. The development of eggs, larvae and pupae was checked daily, and the length and survival of each stage of each individual was recorded. Newly emerging, fully sclerotized adults were measured by ocular micrometer to the nearest $0.1 \mathrm{~mm}$. The adults were fed by the experimental diet, and kept in the glass vials for four months. After a five-month hibernation $\left(+2-+5^{\circ} \mathrm{C}\right.$ at permanent dark), the adults were re-used in the rearing experiments.

Larvae and adults were reared on either a pure diet of seeds (Stellaria media, Capsella bursa-pastoris, Tussilago farfara, Plantago major, Urtica dioica, or Potentilla argentela), or on a pure diet of yellow mealworms (Tenebrio molitor larvae). The seeds of convenient size were taken from the most abundant plants growing in the habitats where the species lived, or those recorded in the literature as being a food resource (Kleine, 1912; Burmeister, 1939; Lindroth, 1945; Bracht Jørgensen \& Toft, 1997; Saska \& Jarošík, 2001).

The results obtained following the protocol above were compared with rearing on a mixed diet of the larvae of $T$. molitor and the seeds of $S$. media and C. bursa-pastoris. More generations were reared on several pure diets. Two generations were reared on C. bursa-pastoris, T. farfara, and T. molitor, and three generations on $S$. media. Beetles reared in the first generation on C. bursa-pastoris were transferred in the second generation either to $S$. media or $T$. molitor, and those transferred to $T$. molitor were put back to C. bursa-pastoris in the third generation.

\section{Statistical analysis}

Survivorship was based on a cohort of freshly hatched $1^{\text {st }}$ instar larvae, with the mean time to death measured in terms of survival to the $1^{\text {st }}, 2^{\text {nd }}$ and $3^{\text {rd }}$ larval instar, pupal and adult stages. The data were described by likelihood ratio tests in which survival was fitted by an exponential function (which is characterised by a constant death rate), and a Weibull function (which is characterised by a continuous increase or decrease in death rate; Appendix I), and tested by a $\chi^{2}$ test. The appropriate likelihood test (exponential or Weibull) was then selected based on the comparisons of the residual deviance and the explanatory power of the models. The structure of the models was checked following Crawley (1993) by error-checking plots for exponential and Weibull data on age at death (see Aitkin et al., 1989). The models were simplified by deletion tests (see Crawley, 1993).

The duration of development was determined for the $1^{\text {st }}, 2^{\text {nd }}$, $3^{\text {rd }}$ larval instars, the pupae, and for the total pre-imaginal development (excluding eggs), with the mean developmental time measured in days. The appropriate transformation of the mean developmental times was chosen by the Box - Cox method (Box \& Cox, 1964, 1982). The adequacy of the transformation was checked by comparing the raw and the transformed data by plotting standardised residuals of the models against fitted values and against explanatory variables, and the ordered residuals against expected order statistics (Crawley, 1993).

The data were analysed by fixed-effect analyses of variances (ANOVAs). Mean times to death, transformed developmental times, and size of emerging adults were the explanatory variables, while larval diet, generation (for larvae reared on pure diets several generations) and sex (for adult size) were factors The a priori notion that individuals reared on the mixed diet survived better, developed faster and emerged larger than those reared on the pure diets, was tested using orthogonal contrasts. Differences among generations on pure diets were compared by LSD tests. A posteriori notions about differences among pure diets were tested using the Scheffé method (Sokal \& Rohlf, 1994).

Calculations were made using general linear modelling in the commercial statistical package GLIM 4.0 (Francis et al., 1994).

\section{RESULTS}

\section{First generation on pure and mixed diets}

Larvae reared on the mixed diet of Tenebrio molitor, Stellaria media and Capsella bursa-pastoris survived better, and developed faster in larger adults than those reared on the pure diets of seeds of S. media, C. bursa-pastoris, Tussilago farfara, Plantago major and Urtica dioica, or the pure diet of Tenebrio molitor larvae (Table 1, Figure 1). The only exception was the rate of pupal development, which was significantly slower on the mixed than on the pure diets (orthogonal contrast of mixed vs. pure diet: $\mathrm{F}=$ 23.38; $\mathrm{df}=1,100 ; \mathrm{P}<0.001$, Table 1). No eggs were laid on the seeds of Potentilla argentela.

Survivorship from the initial cohort of freshly hatched larvae, measured in terms of survival to individual developmental stages, was, in the $1^{\text {st }}$ larval instar, $100 \%$ on the mixed diet, and $95.4-100 \%$ on the pure diets. The values for the $2^{\text {nd }}, 3^{\text {rd }}$ larval instar, pupa, and moulting to adults, respectively, were, on the mixed vs. the pure diets, respectively, 98.3 vs. $45.5-100 \%, 88.3$ vs. $27.3-90.0 \%$, 88.3 vs. $27.3-90.0 \%$, and 81.7 vs. $27.3-62.5 \%$ (Fig. $1 \mathrm{~A}$ ). There were no significant differences in survivorship among the pure diets (ANOVA: $\chi^{2}=9.37$; $\mathrm{df}=5$; NS).

The mean developmental length for the $1^{\text {st }}, 2^{\text {nd }}, 3^{\text {rd }}$ larval instar, pupa, and total ( $1^{\text {st }}$ larval instar - adult) preimaginal development, respectively, were, on the mixed vs. pure diets, respectively, 4.22 vs. $5.00-7.25,6.34$ vs. $6.71-13.00,15.58$ vs. $14.40-26.00,9.92$ vs. $8.33-9.61$, and 37.22 vs. $37.50-52.50$ days (Table 2). The developmental rate thus appeared significantly (Table 1) higher on the mixed than on the pure diets, except for pupa with a significant (Table 1), reverse trend (Fig. 1B, Table 2). The mean developmental time in the $1^{\text {st }}, 2^{\text {nd }}$ larval instar and pupa, was on average about $20 \%$ of the total development time, and, in the $3^{\text {rd }}$ larval instar, about $40 \%$ of the total time. On average, the $3^{\text {rd }}$ instar lasted nearly 3 times longer than the $1^{\text {st }}$ and $2^{\text {nd }}$ instar (Table 2).

Developmental rates also differed among pure diets (Fig. 1B, Table 2). In the $1^{\text {st }}$ instar, beetles developed significantly slower on the larvae of $T$. molitor than on the seeds of S. media, C. bursa-pastoris, T. farfara, $P$. major and $U$. dioica (Scheffé test: $\mathrm{C}=-6.18 \pm 4.94 ; \mathrm{P}<0.05$ ). In the $2^{\text {nd }}$ and $3^{\text {rd }}$ larval instar, the beetles developed significantly slower on the seeds of $U$. dioica than on other pure diets, including $T$. molitor $\left(2^{\text {nd }}\right.$ instar: $\mathrm{C}=-27.07 \pm$ 8.38; $\mathrm{P}<0.05 ; 3^{\text {rd }}$ instar: $\left.\mathrm{C}=-40.27 \pm 10.27 ; \mathrm{P}<0.05\right)$. Consequently, the total pre-imaginal development also appeared significantly slower on the seeds of $U$. dioica than on other pure diets $(\mathrm{C}=-59.43 \pm 14.05 ; \mathrm{P}<0.05)$.

The average adult size on the mixed diet, $7.82 \mathrm{~mm}$, was significantly (Table 1) larger than the average on the pure diets, $7.25 \mathrm{~mm}$ (Fig. 1C). The adults that emerged on the 

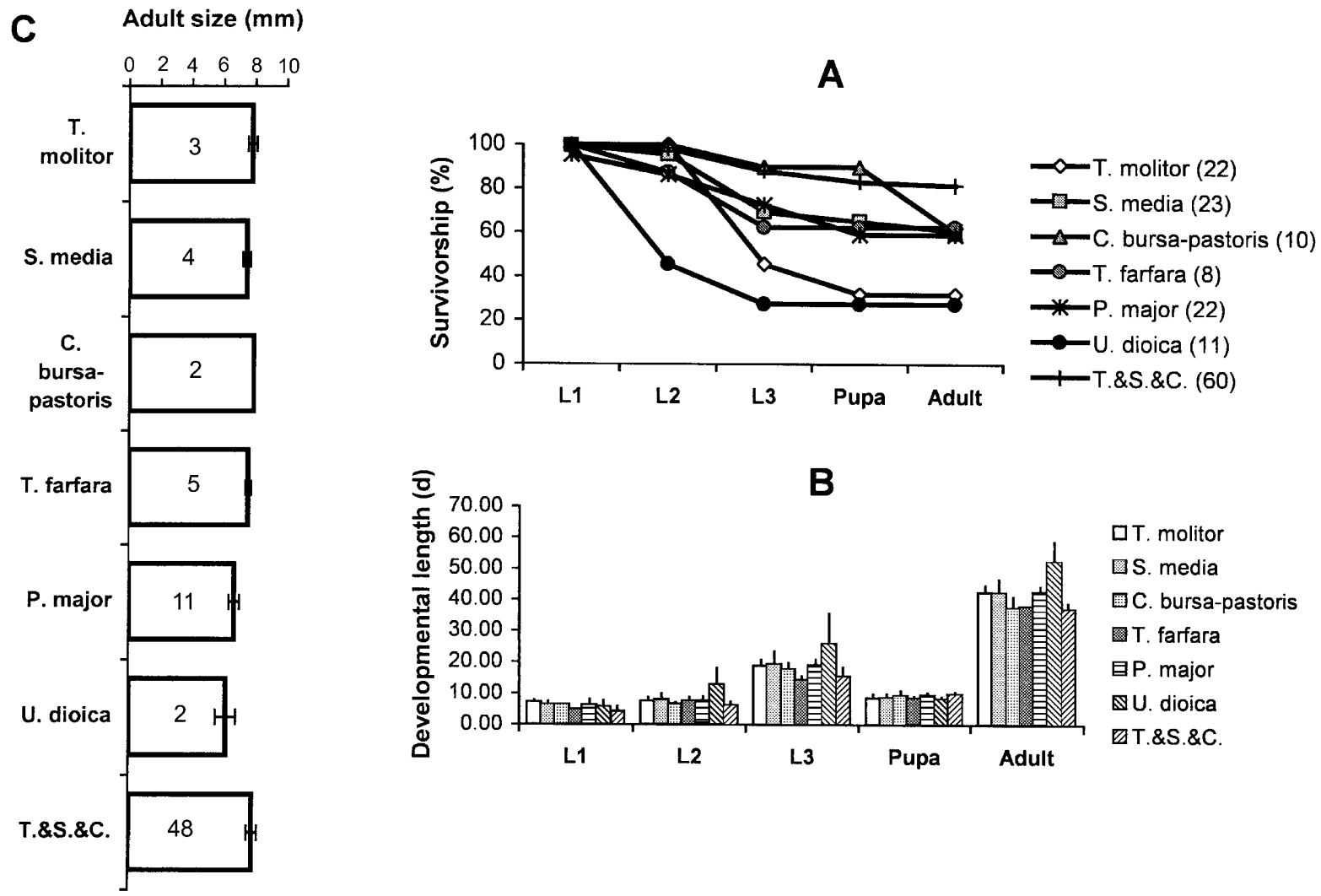

Fig. 1. (A) Mean percentage survivorship (\%); (B) mean developmental length (days, d) for the $1^{\text {st }}(\mathrm{L} 1), 2^{\text {nd }}(\mathrm{L} 2)$, $3^{\text {rd }}(\mathrm{L} 3)$ larval instar, pupa, and total (L1-adult) pre-imaginal development time (Adult); (C) mean size of emerging adults. Individuals of Amara aenea were reared in the first generation on pure (Tenebrio molitor, Stellaria media, Capsella bursa-pastoris, Tussilago farfara, Plantago major, Urtica dioica) and mixed (Tenebrio \& Stellaria \& Capsella) diets. The figures in legends (A) and bars (C) are sample sizes, cross lines (B, C) are standard deviations.

seeds of $U$. dioica were smaller than on the other pure diets, but, unlike the developmental rate, this difference was not significant $(\mathrm{C}=6.53 \pm 13.45$; NS $)$, probably due to small sample size on $U$. dioica (Fig. 1C). The average adult size was not significantly affected by the sex of emerging adults, nor by the interaction between sex and diet (Table 3).

\section{More generations on pure diets}

When reared on the same pure diet for further generations, survivorship, and in most cases also duration of

TABLE 1. The results of ANOVA tables of differences among diets, and orthogonal contrasts of differences between mixed vs. pure diets, for survival (mean survivorship, days), duration of development (developmental rate, day ${ }^{-1}$ ) and adult size (mm). Individuals of Amara aenea reared in the first generation on pure (Tenebrio molitor, Stellaria media, Capsella bursa-pastoris, Tussilago farfara, Plantago major, Urtica dioica) and mixed (Tenebrio \& Stellaria \& Capsella) diets. $* *=\mathrm{P}<0.01, * * *=\mathrm{P}<0.001$.

\begin{tabular}{|c|c|c|c|c|}
\hline \multirow{3}{*}{$\begin{array}{l}\text { Survivorship } \\
\text { Sitness component }\end{array}$} & & Source of variation & $\mathrm{Df}$ & $\chi^{2}$ or F-test \\
\hline & & Among diets & 6 & $20.23 * *$ \\
\hline & & Mixed vs. pure diets & 1 & $9.22 * *$ \\
\hline \multirow[t]{10}{*}{ Developmental rate } & Larva 1 & Among diets & 6,99 & $3.53 * *$ \\
\hline & & Mixed vs. pure diets & 1,104 & $21.54 * * *$ \\
\hline & Larva 2 & Among diets & 6,132 & $8.11 * * *$ \\
\hline & & Mixed vs. pure diets & 1,137 & $39.06 * * *$ \\
\hline & Larva 3 & Among diets & 6,104 & $9.36 * * *$ \\
\hline & & Mixed vs. pure diets & 1,109 & $33.58 * * *$ \\
\hline & Pupa & Among diets & 6,95 & $7.05 * * *$ \\
\hline & & Mixed vs. pure diets & 1,100 & $23.38 * * *$ \\
\hline & Larva 1 - adult & Among diets & 6,36 & $13.32 * * *$ \\
\hline & & Mixed vs. pure diets & 1,41 & $31.69 * * *$ \\
\hline \multirow[t]{2}{*}{ Adult size } & & Among diets & 6,68 & $25.75 * * *$ \\
\hline & & Mixed vs. pure diets & 1,73 & $41.42 * * *$ \\
\hline
\end{tabular}


TABLE 2. The mean developmental time (days), standard deviation (SD) and sample size (n) for the $1^{\text {st }}(\mathrm{L} 1), 2^{\text {nd }}(\mathrm{L} 2), 3^{\text {rd }}(\mathrm{L} 3)$ instar larvae, pupae, and total (L1-adult) pre-imaginal development. Otherwise as in Table 1.

\begin{tabular}{|c|c|c|c|c|c|c|}
\hline Diet & & L1 & $\mathrm{L} 2$ & $\mathrm{~L} 3$ & Pupa & Total $^{1}$ \\
\hline \multirow[t]{3}{*}{ Tenebrio molitor larvae } & Mean & 7.25 & 7.57 & 18.90 & 8.57 & 42.50 \\
\hline & SD & 0.50 & 1.29 & 1.97 & 1.27 & 2.12 \\
\hline & $\mathrm{n}$ & 4 & 21 & 10 & 7 & 2 \\
\hline \multirow[t]{3}{*}{ Stellaria media } & Mean & 6.45 & 8.14 & 19.40 & 8.87 & 42.38 \\
\hline & SD & 0.93 & 1.88 & 4.22 & 1.06 & 4.27 \\
\hline & $\mathrm{n}$ & 11 & 22 & 15 & 15 & 8 \\
\hline \multirow[t]{3}{*}{ Capsella bursa-pastoris } & Mean & 6.50 & 6.71 & 17.78 & 9.56 & 37.50 \\
\hline & SD & 0.02 & 0.49 & 2.11 & 1.33 & 3.54 \\
\hline & $\mathrm{n}$ & 2 & 7 & 9 & 9 & 2 \\
\hline \multirow[t]{3}{*}{ Tussilago farfara } & Mean & 5.00 & 7.67 & 14.40 & 8.60 & 38.00 \\
\hline & $\mathrm{SE}$ & 0.00 & 1.21 & 1.14 & 0.55 & 0.00 \\
\hline & $\mathrm{n}$ & 1 & 6 & 5 & 5 & 1 \\
\hline \multirow[t]{3}{*}{ Plantago major } & Mean & 6.32 & 7.84 & 19.25 & 9.61 & 42.70 \\
\hline & $\mathrm{SE}$ & 1.73 & 1.17 & 1.69 & 0.65 & 1.70 \\
\hline & $\mathrm{n}$ & 19 & 19 & 16 & 13 & 11 \\
\hline \multirow[t]{3}{*}{ Urtica dioica } & Mean & 5.80 & 13.00 & 26.00 & 8.33 & 52.50 \\
\hline & $\mathrm{SE}$ & 1.87 & 5.20 & 9.64 & 0.58 & 6.36 \\
\hline & $\mathrm{n}$ & 10 & 5 & 3 & 3 & 2 \\
\hline \multirow[t]{3}{*}{ Potentilla argentela } & Mean & - & - & - & - & - \\
\hline & $\mathrm{SE}$ & - & - & - & - & - \\
\hline & $\mathrm{n}$ & 0 & 0 & 0 & 0 & 0 \\
\hline \multirow[t]{3}{*}{ T. molitor \& S. media \& C. bursa-pastoris } & Mean & 4.22 & 6.34 & 15.58 & 9.92 & 37.22 \\
\hline & $\mathrm{SE}$ & 1.65 & 1.08 & 2.82 & 0.70 & 1.83 \\
\hline & $\mathrm{n}$ & 59 & 59 & 53 & 50 & 18 \\
\hline
\end{tabular}

${ }^{1}$ Total mean developmental time does not correspond to the sum of L1-L3 and pupal stages, as only individuals surviving to the adult stage are included in the analysis.

development, did not change when the beetles were reared on the seeds of C. bursa-pastoris and S. media. Beetle survivorship and developmental rate remained the same on C. bursa-pastoris for two generations (Fig. 2), and for three generations on $S$. media. In the latter case, the exception was the developmental rate in the second generation, that was significantly faster than in the first and the third generation for the second larval instar and the total pre-imaginal development (Fig. 3). No eggs were laid on the same diet in the second generation by females that were reared in the first generation on T. molitor and T. farfara.

When beetles were reared for further generations, but switching to a different diet each generation, survivorship significantly decreased in successive generations. It was

TABLE 3. ANOVA table of differences among diets and sex in adult size (mm). NS = not significant. Otherwise as in Table 1.

\begin{tabular}{lcccc}
\hline Source & SS & Df & MS & F \\
\hline Among diets & 16.16 & 6 & 2.7666 & $25.52 * * *$ \\
Sex & 0.007519 & 1 & 0.007519 & $0.069 \mathrm{NS}$ \\
$($ Sex $) \times($ diet $)$ & 0.3832 & 5 & 0.0766 & $0.707 \mathrm{NS}$ \\
Error & 6.7219 & 62 & 0.1084 & \\
Total & 23.273 & 74 & & \\
\hline
\end{tabular}

so for beetles transferred from C. bursa-pastoris to $S$. media (Fig. 4), and for those transferred from C. bursapastoris to T. molitor (Fig. 5). Developmental rate remained the same for beetles transferred from C. bursapastoris to T. molitor (Fig. 5), and, in most cases, also for those transferred from C. bursa-pastoris to $S$. media. In the latter case, the exception was for the third larval instar and pupa, for which the developmental rate was significantly faster after the transfer to $S$. media (Fig. 4). When in the third generation beetles reared in the second generation on T. molitor were returned back to C. bursapastoris, only five $2^{\text {nd }}$ instar larvae were recorded.

\section{DISCUSSION}

The probability of death always increased with increasing duration of development. This was indicated by the Weibull likelihood ratio test being a significantly better predictor of survivorship than the exponential model. The duration of development was best described by its reciprocal value, the developmental rate $\left(\right.$ days $\left.^{-1}\right)$. Models using developmental rates had the smallest residual deviance and the largest explanatory power. Their standardized residuals indicated constant variance, their deviates were normally distributed, and their standardized residuals did not show any systematic pattern. 

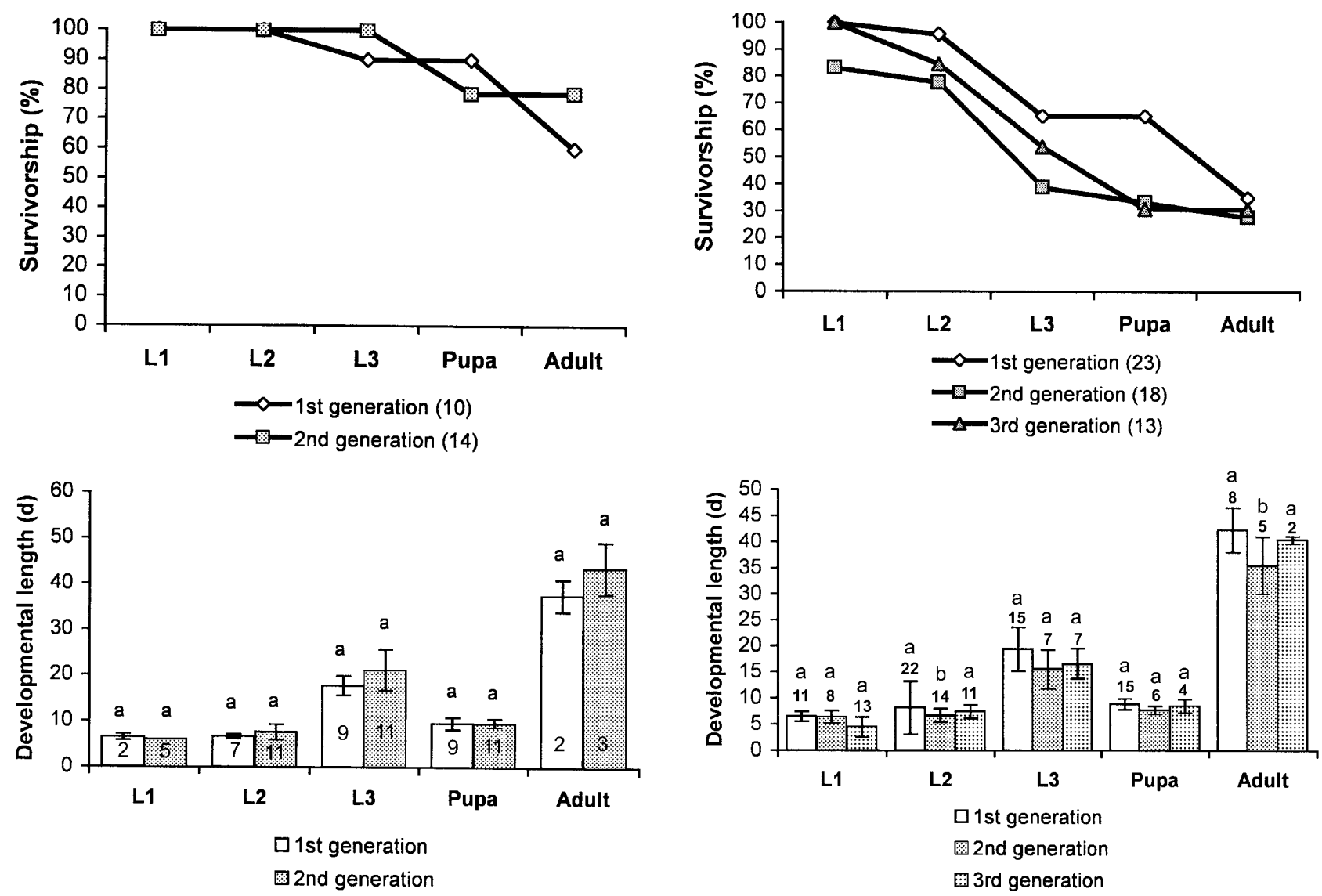

Fig. 2. Mean percentage survivorship (above) and mean developmental length (days, d) for the $1^{\text {st }}(\mathrm{L} 1), 2^{\text {nd }}(\mathrm{L} 2), 3^{\text {rd }}(\mathrm{L} 3)$ larval instar, pupa, and total (L1-adult) pre-imaginal development time (Adult). Individuals of Amara aenea were reared on the seeds of Capsella bursa-pastoris in the first and the second generation. Cross lines are standard deviations and figures in bars sample sizes. Lines and bars with the same letter do not differ significantly in LSD tests $(\mathrm{p}<0.05)$.

The duration of development, survivorship and adult size were used as characteristic of fitness of Amara aenea. Following the usual practice (e.g. Sibly \& Calow, 1986), we assumed that fitness is equivalent to the value of the intrinsic rate of increase. The intrinsic rate of increase consists of the duration of development, survivorship and fecundity; the only component of fitness not directly measured was fecundity. Since female fecundity is directly proportional to body size (Honěk, 1993), the size of emerging adults served as a surrogate of fecundity. The hypothesis that the larvae are primary omnivorous (Saska \& Jarošík, 2001) thus could be tested by assessment of all crucial components of fitness.

The evidence that the larvae of $A$. aenea are primary omnivorous was obtained by revealing that the larvae reared on the mixed diet of insects and seeds survived better, and developed faster to became larger adults than those reared on the pure diets of seeds or insects.

The average size of the adults on the mixed and the pure diets is consistent with the average size of 50 field collected adults, which was $7.5 \mathrm{~mm}$ (Hưrka, 1996). Thus, the average size of adults reared on the mixed diet, 7.82 $\mathrm{mm}$, was larger than those collected in the field, while the

Fig. 3. Individuals of Amara aenea reared on the seeds of Stellaria media in the first, second and third generation. Otherwise as in Fig. 2.

average size of individuals reared on the pure diets, 7.25 $\mathrm{mm}$, was smaller than in the field. The whole range of sizes recorded in the field, which is $6.1-8.4 \mathrm{~mm}$. (Hůrka, 1996), suggests that the seeds of Urtica dioica, with the average size of adults $6.16 \mathrm{~mm}$, are a very poor diet.

That the rate of pupal development was slower on the mixed diet than on the pure diets is not surprising, since the beetles do not feed in the pupal stage. The development in pupa thus can be long, because the emerging adults on the mixed diet are large, and may require a longer time for metamorphosis (cf. Sequeira \& Mackauer, 1992).

The length of the third instar varied greatly, but it generally lasted nearly 3 times longer than the first and second instar, and formed about $40 \%$ of the total preimaginal development time. Similar results were previously obtained for other Amara species (Hůrka \& Jarošík, 2001; Saska \& Jarošík, 2001). The third instar is the largest, longest lasting and most voracious stage, and probably determines, in a great extent, the final size of the adult (Hůrka \& Jarošík, 2001).

No egg production was recorded on the seeds of Potentilla argentela, and a slow larval development resulted when reared on the seeds of Urtica dioica. The first larval instar reared on the larvae of T. molitor developed slowly, but the following stages did not differ from larvae reared on the seeds. It suggests that the freshly hatched larvae could be better adapted to eating seeds than insects. 

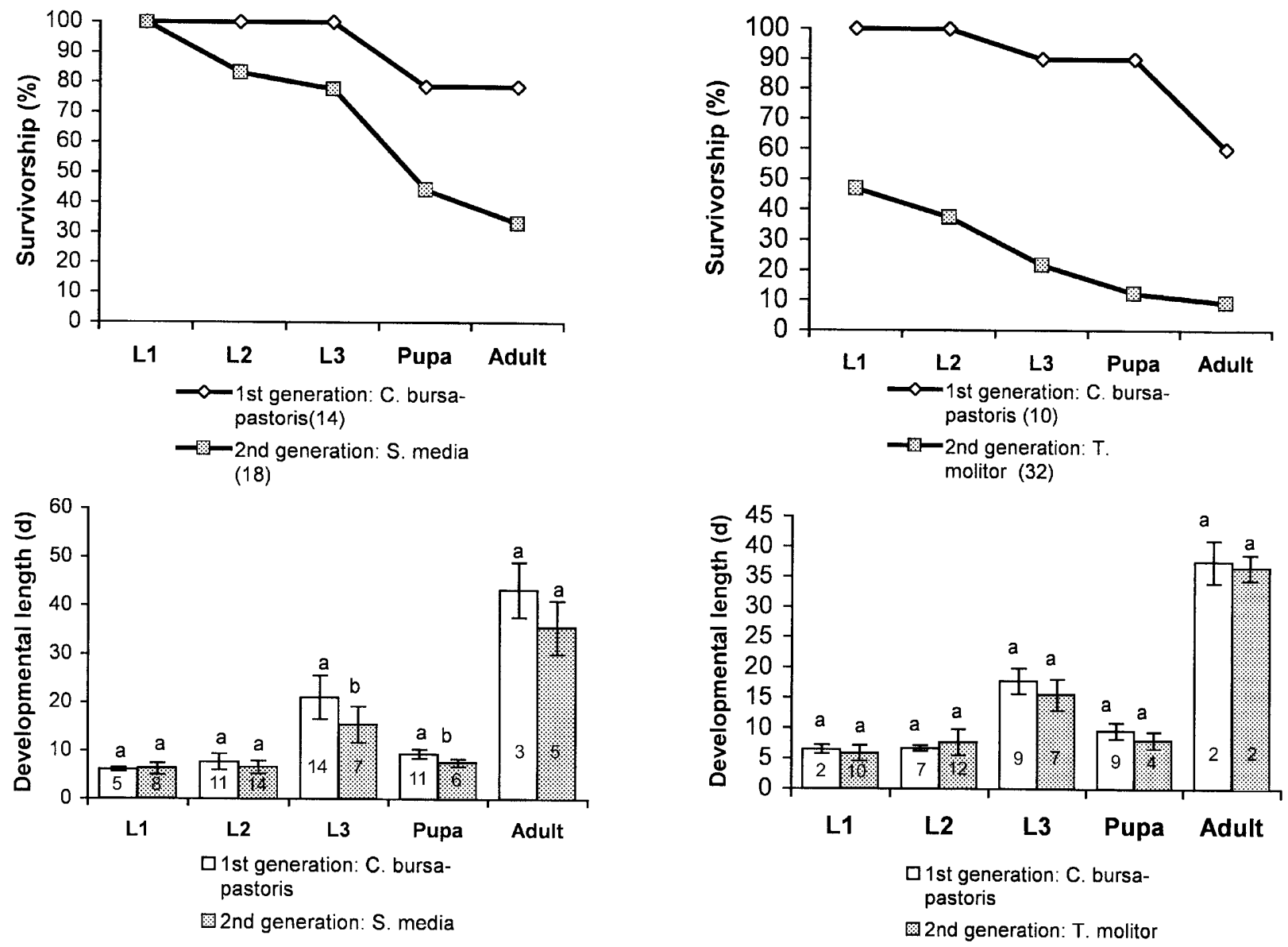

Fig. 4. Individuals of Amara aenea reared on the seeds of Capsella bursa-pastoris in the first, and on the seeds of Stellaria media in the second generation. Otherwise as in Fig. 2.

When the beetles were reared on the same pure diet for several generations, survivorship, and in most cases also duration of development, did not change. However, when the beetles were reared on different pure diets each generation, their survivorship significantly decreased in successive generations. It suggests that omnivorous larvae of A. aenea are able to adapt to a pure diet, similarly as aphidophagous larvae of ladybirds (Rana et al., 2002).

When subsequent generations are reared on different diets, increasing developmental rate, accompanied by decreasing survivorship, were observed for the third instar larvae and pupae in the second generation when reared on S. media. Increasing developmental rate, associated with increasing mortality, could be caused by the survival of the individuals with the fastest development rates, while the rest succumb the unsuitable food (Jarošík et al., 2002).

Carnivory is generally considered to be the plesiomorphic character state for the larvae of carabids (Hůrka, 1996). Larval carnivory is preserved at least in some species of the subgenus Amara, as with the larvae of A. communis aggregate (Hůrka \& Jarošík, 2001), or, with a more closely related species to A. aenea, Amara proxima Putzeys (Hůrka, 1998). The evolution of granivory was probably gradual, with the omnivory of $A$. aenea possibly being a transient state from carnivory to granivory. The

Fig. 5. Individuals of Amara aenea reared on the seeds of Capsella bursa-pastoris in the first, and on the larvae of Tenebrio molitor in the second generation. Otherwise as in Fig. 2.

evolution of granivory was associated with an increase in developmental time on insect diets, probably as a consequence of a decreasing ability of digestion (Allen \& Hagley, 1982; Bracht Jørgensen \& Toft, 1997). This may be the case with the increased developmental time associated with an insect diet observed with the first larval instar of $A$. aenea. Such an increase may lead to a gradual loss of the ability to complete post-embryonic development on an insect diet (Saska \& Jarošík, 2001).

ACKNOWLEDGEMENTS. The work was supported by MŠMT grant no. J13/98113100004. The senior author acknowledges the

\section{ApPendix I. Survival analysis}

The differences in survivorship were fitted by a likelihood function described by two parameters, the mean time to death, $\mu$, and a shape parameter, $\alpha$. The mean time to death was the time to when $50 \%$ of the larvae have died. The shape parameter indicated the appearance of the mortality curve. The proportion $P$ of larvae that have died as a function of time, $t$, was described as

$\mathrm{P}(\mathrm{t})=\mathrm{e}^{-\lambda t \alpha}$

where $\lambda=\mu^{\alpha}$. The model indicates on exponential distribution of survivorship if $\alpha$ is equal to 1 , and to Weibull distribution if $\alpha$ significantly differs from 1 . With a Weibull distribution, $\alpha<1$ indicates a decrease in death rate with increasing time, and $\alpha>1$ an increase in death rate with time. 
support of this study by the Grant Agency of the Czech Republic, Praha, Grant No. 522/97/0271.

\section{REFERENCES}

Aitkin M., Anderson D., Francis B. \& Hinde J. 1989: Statistical Modelling in GLIM. Clarendon Press, Oxford, $569 \mathrm{pp}$.

Allen R.T. 1979: The occurrence and importance of ground beetles in agricultural and surrounding habitats. In: Erwin T. L., Ball G.E., Whitehead D.A. \& Halpern A.L. (eds): Carabid Beetles: Their Evolution, Natural History, and Classification. Junk, The Hague, pp. 485-505.

BílÝ S. 1971: The larva of Amara (Celia) erratica (Duftschmid) and notes on the bionomy of this species. Acta Entomol. Bohemoslov. 68: 89-94.

BílÝ S. 1972: The larva of Amara (Amara) eurynota (Panzer) (Coleoptera: Carabidae) and notes on the bionomy of this species. Acta Entomol. Bohemoslov. 69: 324-329.

BílÝ S. 1975: Larvae of the genus Amara (subgenus Celia Zimm.) from Central Europe (Coleoptera: Carabidae). Studie CSAV 13: 1-74.

Box G.E.P \& Cox D.R. 1964: An analysis of transformations. $J$. Royal Statistic. Soc. B 26: 211-252.

Box G.E.P. \& Cox D.R. 1982: An analysis of transformations revisited. J. Amer. Statistic. Assoc. 77: 209-210.

Bracht Jørgensen H. \& Toft S. 1997: Role of granivory and insectivory in the life cycle of carabid beetle Amara similata. Ecol. Entomol. 22: 7-15.

Burakowski B. 1967: Biology, ecology and distribution of Amara pseudocommunis Burak. (Coleoptera: Carabidae). Ann. Zool., Warszawa 24: 486-523.

Burmeister F. 1939: Biologie, Ökologie und Verbreitung der Europäischen Käfer, I. Band: Adephaga, Caraboidea. Hans Goecke Verlag, Krefeld, 206 pp.

CRAwley J.M. 1993: GLIM for Ecologists. Blackwell, Oxford, $379 \mathrm{pp}$.

DeSENDER K. 1988: The larvae of Amara aenea (De Geer, 1774) and Amara familiaris (Duftschmid, 1812) (Coleoptera: Carabidae). Bull. Annls. Soc. R. Belge Entomol. 124: 153-164.

Desender K., Pollet M. \& Goosens R. 1986: The larva of Amara curta Dejean, 1828 and Amara tibialis (Paykull, 1798) (Col., Carabidae) with notes on the life cycle of both species. Biol. Jb. Dodonaea 54: 104-115.

De Snoo G.R., van der Poll R.J. \& de Leeuw J. 1995: Carabids in sprayed and unsprayed crop edges of winter wheat, sugar beet and potatoes. In: Toft S. \& Riedel W. (eds): Arthropod natural enemies in arable land - I. Density, spatial heterogeneity and dispersal. Acta Jutlandica 70: 199-211.

FoRSYTHE T.G. 1982: Feeding mechanisms of certain ground beetles (Coleoptera: Carabidae). Col. Bull. 36: 26-73.

Francis B., Green M. \& Payne C. (eds) 1994: The GLIM System. Release 4 Mamal. Clarendon Press, Oxford, 821pp.

Hengeveld R. 1980: Polyphagy, oligophagy and food specialization in Ground Beetles (Coleoptera: Carabidae). Neth. J. Zool. 30: $564-584$

HoNĚK A. 1993: Intraspecific variation in body size and fecundity of insects: a general relationship. Oikos 66: 483-492.

HoNĚK A. \& JAROŠ́́K V. 2000: The role of microclimate, seed and aphid predation in diversification of field communities of Carabidae (Coleoptera). Eur. J. Entomol. 97: 517-525.

HonĚK A., MARtínKová Z. \& JARošík V. 2003: Carabids as seed predators. Eur. J. Entomol. 100: in press.
HƯRKA K. 1996: Carabidae of the Czech and Slovak Republics. Carabidae Ceské a Slovenské republiky. Zlín, Kabourek, 565 pp.

HŮRKA K. 1998: Larval taxonomy, development and diet of Amara (Amara) famelica, A. (A.) littorea and A. (A.) proxima (Coleoptera: Carabidae: Amarina). Acta Soc. Zool. Bohem. 62: 105-113.

HứRKA K. \& Duchác̆ V. 1980a: Larval descriptions and the breeding type of the central European species of Amara (Curtonotus) (Coleoptera, Carabidae). Acta Entomol. Bohemoslov. 77: $258-270$

HƯRKA K. \& DUCHÁČ V. 1980b: Larvae and the breeding type of the central European species of the subgenera Bradytus and Pseudobradytus (Coleoptera: Carabidae, Amara). Věst. Čs. Společ. Zool. 44: 166-182.

HỨRKA K. \& JARošík V. 2001: Development, breeding type and diet of members of the Amara communis species aggregate (Coleoptera: Carabidae). Acta Soc. Zool. Bohem. 65: 17-23.

JARošír V., HonĚK A., Dixon A.F.G. 2002: Rate isomorphy in insects and mites. Am. Nat. 160: 497-510.

JARoš́́K V. \& HƯRKA K. 1986: Die Coleopterenfauna des Rapsfelds. Věst. Čs. Společ. Zool. 50: 192-212.

KLeine R. 1912: Carabiden als Pflanzenfresser. Entomol. Bl. 10/11: $282 \mathrm{p}$.

Klerne R. 1914: Zur Biologie der Amara-Arten. Entomol. Bl. 1/2: $57 \mathrm{p}$.

Kokta C. 1988: Beziehungen zwischen der Verunkrautung und phytophagen Laufkäfern der Gattung Amara. Mitt. Biol. Bundesanstalt Land- Forstwirtschaft 247: 139-145.

LindRoth C.H. 1945: Die fennoskandischen Carabidae. I. Götteborgs Kungl. Vetensh. Vitterh. Samh. Handling, Ser. B 4: $1-710$.

LufF M.L. 1993: The Carabidae (Coleoptera) larvae of Fennoscandia and Denmark. Fauna Entomol. Scandinavica 27: $1-176$

LuKa H., Pfiffner L. \& Wyss E. 1998: Amara ovata und A. similata (Coleoptera: Carabidae), zwei phytophage Laufkäferarten in Rapsfeldern. Bull. Soc. Entomol. Suisse 71: 125-131.

Rana J.S., Dixon A.F.G. \& Jarošík V. 2002: Costs and benefits of prey specialization in a generalist insect predator. J. Anim. Ecol. 71: 15-22.

SASKA P. \& JARoší́ V. 2001: Laboratory study of larval food requirements in nine species of Amara (Coleoptera: Carabidae). Plant Protect. Sci. 37: 103-110.

Sequetra R. \& MaCKauer M. 1992: Covariance of adult size and developmental time in the parasitoid wasp Aphidius ervi in relation to the size of its host, Acyrthosiphon pisum. Evol. Ecol. 6: 34-44.

Sibly R.M. \& Calow P.C. 1986: Physiological Ecology of Animals. Blackwell, Oxford, $396 \mathrm{pp}$.

SoKal R. \& RohlF F.J. 1981: Biometry. Freeman, San Francisco, $859 \mathrm{pp}$.

Thompson R.G. 1979: A systematic study of larvae in the tribes Pterostichini, Morionini, and Amarini (Coleoptera: Carabidae). Bull. Ark. Univ. Agric. Exp. Stn. 837: 1-105.

Zetto Brandmayr T., Giglio A., Marano I. \& Brandmayr P. 1998: Morphofunctional and ecological features in carabid (Coleoptera) larvae. Mus. Reg. Sci. Nat. Torino 1998: 449-490.

Received July 26, 2002; revised September 19, 2002; accepted November 21, 2002 